\title{
High-Energy and High-Power-Density Potassium lon Batteries Using Dihydrophenazine-Based Polymer as Active Cathode Material
}

Filipp A. Obrezkov, ${ }^{\dagger}$ Vahid Ramezankhani, ${ }^{\dagger}{\text { Ivan } \text { Zhidkov, }^{\ddagger} \text { (๑) Valerii F. Traven, }}^{\S}$ Ernst Z. Kurmaev, ${ }^{\ddagger} \|$ Keith J. Stevenson, ${ }^{\dagger}$ and Pavel A. Troshin ${ }^{*},^{\dagger}, \perp^{(0}$

\author{
${ }^{\dagger}$ Skolkovo Institute of Science and Technology, Nobel St. 3, Moscow 143026, Russia \\ ${ }^{\ddagger}$ Institute of Physics and Technology, Ural Federal University, Mira str. 19, Yekaterinburg 620002, Russia \\ ${ }^{\S}$ D. I. Mendeleev University of Chemical Technology of Russia, Miusskaya Sq. 9, Moscow 125047, Russia \\ ${ }$ M. N. Mikheev Institute of Metal Physics of Ural Branch of Russian Academy of Sciences, S. Kovalevskoi str. 18, Yekaterinburg \\ 620108, Russia \\ ${ }^{\perp}$ Institute for Problems of Chemical Physics of Russian Academy of Science, Acad. Semenov ave. 1, Chernogolovka, Moscow Region \\ 142432, Russia
}

\section{Supporting Information}

ABSTRACT: Polymeric aromatic amines were shown to be very promising cathodes for lithium-ion batteries. Surprisingly, these materials are scarcely used for designing post-lithium batteries. In this Letter, we investigate the application of the high-voltage poly( $N$-phenyl-5,10-dihydrophenazine) (p-DPPZ) cathodes for Kion batteries. The designed batteries demonstrate an impressive specific capacity of $162 \mathrm{mAh} \mathrm{g}^{-1}$ at the current density of $200 \mathrm{~mA} \mathrm{~g}^{-1}$, operate efficiently at high current densities of $2-10 \mathrm{~A} \mathrm{~g}^{-1}$, enabling charge and discharge within $\sim 1-4 \mathrm{~min}$, and deliver the specific capacity of $125-145 \mathrm{mAh} \mathrm{g}^{-1}$ with a retention of 96 and $79 \%$ after 100 and 1000 charge-discharge cycles, respectively. Finally, these K-ion batteries with polymeric $\mathrm{p}$-DPPZ cathodes showed rather outstanding specific power of $>3 \times 10^{4}$ $\mathrm{W} \mathrm{kg}{ }^{-1}$, thus paving a way to the design of ultrafast and durable high-capacity metalion batteries matching the increasing demand for high power and high energy density electrochemical energy storage devices.

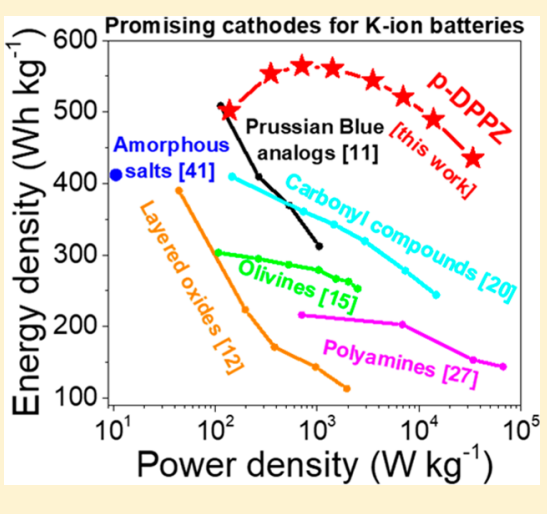

$\mathrm{Fe}^{\mathrm{a}}$ or decades, lithium-ion batteries have remained the leading technology in the market of electrochemical energy storage devices. ${ }^{1}$ However, a low abundance of lithium in the Earth's crust ${ }^{2}$ hinders the potential application of this technology with respect to massive scale-up adoption, for example, for bulk energy storage. A significant concern is that the rapid growth and production of various portable electronics and electric vehicles utilizing lithium-ion battery materials as a power source will cascade to the depletion of lithium reserves ${ }^{3}$ and a significant increase in prices for lithium and other elements such as $\mathrm{Co}$ and $\mathrm{Ni}^{4}$

These circumstances have boosted interest in and provided an impetus for the development of efficient post-lithium electrochemical energy storage technologies that do not involve supply limited elements such as lithium, cobalt, nickel, and other transition-metals. Potassium-ion batteries represent one of the most promising research directions, as indicated by the exponential growth in the number of relevant publications. ${ }^{5}$ Indeed, there are virtually unlimited resources of potassium in the Earth's crust and oceans compared with lithium, which dictates a much lower price of this element. ${ }^{6}$ Additionally, potassium has a lower redox potential ${ }^{6}$ and demonstrates higher diffusion coefficient than sodium due to solvation effects in electrolytes. Another important advantage of potassium over sodium is its ability to intercalate into graphite, which is undoubtedly the cheapest and most widely used anode material for rechargeable metal-ion batteries. ${ }^{7}$

We note that in the development of K-ion batteries, Prussian blue (PB) analogs ${ }^{8-11}$ represent the most intensively studied family of cathode materials for K-ion batteries due to their availability, impressive practical energy densities (up to 509 Wh $\mathrm{kg}^{-1}$ ), high redox potentials, satisfactory rate capabilities, and cycling stabilities. The highest capacity of $148 \mathrm{mAh} \mathrm{g}^{-1}$ was reported by Piernas-Muñoz et al. ${ }^{9}$ for $\mathrm{K}_{1.59} \mathrm{Fe}_{2.20}(\mathrm{CN})_{6}$, although it utilized sodium-based electrolyte $\mathrm{NaPF}_{6}$. Among the truly potassium-ion batteries, the highest practical gravimetric capacity of $142 \mathrm{mAh} \mathrm{g}^{-1}$ was demonstrated for $\mathrm{K}_{1.89} \mathrm{Mn}\left[\mathrm{Fe}(\mathrm{CN})_{6}\right]_{0.92} \cdot 0.75 \mathrm{H}_{2} \mathrm{O} .^{11}$

Besides the $\mathrm{PB}$ analogs, various layered transition-metal oxides are also explored as high-capacity cathode materials for potassium-ion batteries. ${ }^{12-14}$ For example, the capacities of $178^{12}$ and $140^{13} \mathrm{mAh} \mathrm{g}^{-1}$ were achieved for $\mathrm{K}_{0.7} \mathrm{Fe}_{0.5} \mathrm{Mn}_{0.5} \mathrm{O}_{2}$ and P3-type $\mathrm{K}_{0.5} \mathrm{MnO}_{2}$, respectively. However, this group of materials suffers from poor rate capability and cycling stability

Received: July 13, 2019

Accepted: August 22, 2019

Published: September 7, 2019 
and low average discharge potentials of $<3 \mathrm{~V}$. Olivines ${ }^{15,16}$ represent another promising family of cathode materials for potassium-ion batteries, demonstrating excellent cycling stabilities, good rate capabilities, and high discharge potentials of $>3.9 \mathrm{~V}$. Unfortunately, these materials show inferior gravimetric capacities and energy densities in comparison with the $\mathrm{PB}$ analogs and layered transition-metal oxides. Indeed, the specific capacity of $73 \mathrm{mAh} / \mathrm{g}$ reached for $\mathrm{KVOPO}_{4}$ represents one of the highest values reported for this group of materials. ${ }^{15}$

Organic redox-active compounds are actively explored as a highly promising alternative to conventional inorganic cathodes for metal-ion batteries. Indeed, organic materials are composed of abundant elements such as $\mathrm{C}, \mathrm{H}, \mathrm{N}, \mathrm{O}$ and $\mathrm{S}$, forming the fundamental basis of all living organisms on our planet. Organic materials can be produced entirely from renewable resources. In addition, batteries based on organic materials and containing no heavy metals in their structure can be utilized and recycled as an ordinary household waste. Therefore, organic batteries can be considered as an environment-friendly solution for electrochemical energy storage.

Importantly, light chemical elements forming organic redoxactive species can enable potentially much higher specific capacities compared with standard cathodes based on inorganic oxides and other inorganic polyanion compounds. Organic compounds have already shown an impressive performance in lithium-ion and sodium-ion batteries, $3,17-19$ yet organic cathodes for potassium-ion batteries are still in the infancy of their development. ${ }^{5-7}$ Among the very few reported examples, carbonyl compounds have demonstrated the best characteristics to date. ${ }^{20-24}$ Recently, a specific capacity of 260 $\mathrm{mAh} \mathrm{g}^{-1}$ was delivered by poly(pentacenetetraonesulfide) (PPTS) cathodes operating at a low current density $(100 \mathrm{~mA}$ $\mathrm{g}^{-1}$ ), whereas a very decent value of $167 \mathrm{mAh} \mathrm{g}^{-1}$ was reached at a high current density of $10 \mathrm{~A} \mathrm{~g}^{-1} .^{20}$ The main drawback of carbonyl compounds is their low discharge potential of $\sim 2 \mathrm{~V}$, which severely limits the achievable energy density, which is the main figure of merit for energy storage devices.

The problem of low discharge potentials can be solved using other families of organic redox-active compounds such as nitroxyl-based radical-ion polymers, conductive polymers (e.g., polyaniline or polypyrrole), and polymerized aromatic amines. ${ }^{25,26}$ Amine-based polymers offer exceptional promise as organic cathodes for metal-ion batteries because they can potentially deliver high specific capacities in addition to optimal discharge potentials of $\sim 4 \mathrm{~V}$, excellent rate capability, and good operation stability. ${ }^{26-28}$ However, among all known polymeric arylamines, only poly $\left(N, N^{\prime}\right.$-diphenyl-p-phenylenediamine) (PDPPD) ${ }^{28}$ and polytriphenylamine (PTPA) ${ }^{29}$ were previously explored as cathodes for K-ion batteries, with decent reported specific capacities and energy densities of up to 63 $\mathrm{mAh} \mathrm{g}^{-1}$ and $216 \mathrm{Wh} \mathrm{kg}^{-1}$. However, a much broader range of rationally designed materials should be investigated to unravel a full potential of polyarylamine-type cathodes in potassium batteries.

Herein we investigated poly $(N$-phenyl-5,10-dihydrophenazine) $\left(\mathrm{p}-\mathrm{DPPZ} \mathrm{Z}^{30}\right)$ and demonstrated that it represents one of the most promising organic cathode candidates for $\mathrm{K}$-ion batteries. We synthesized p-DPPZ following the originally reported method ${ }^{30}$ based on the reduction of phenazine to 5,10-dihydrophenazine and the following Buchwald-Hartwig condensation of the latter with 1,4-dibromobenzene (Scheme 1 , details are given in the Supporting Information).
Scheme 1. Synthesis of p-DPPZ

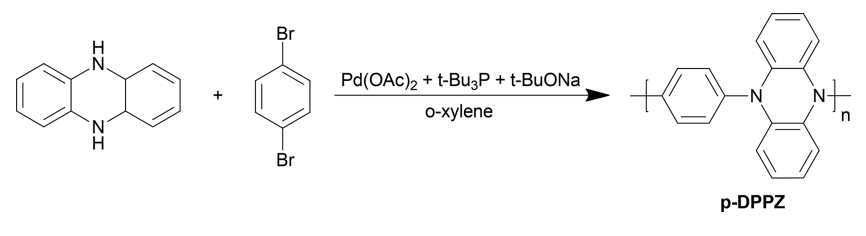

The electrochemical tests were performed using twoelectrode CR2032 coin-type cells with the working electrode based on the p-DPPZ composite with super-P conductive carbon filler and polyvinylidene difluoride (PVDF) binder deposited on the $\mathrm{Al}$ current collector while the metallic potassium was serving as the anode. (The details are provided in the Supporting Information).

Carbonate-based electrolytes represent the gold standard for lithium-ion batteries. In particular, the commercially available 1 $\mathrm{M} \mathrm{LiPF}_{6}$ in a 1:1 v/v mixture of ethylene carbonate (EC) and dimethyl carbonate (DMC) is the electrolyte formulation most commonly used in research laboratories due to its high ionic conductivity and good electrochemical stability (window up to $4.3 \mathrm{~V}),{ }^{31}$ which enable efficient battery operation with the vast majority of known cathode materials. On the contrary, we note that there is no universal electrolyte formulation suitable for various potassium-ion batteries. Frequently, cathode materials for K-ion batteries possess high redox potentials and additionally show considerable overpotentials (Coulombic inefficiencies) toward charge and discharge cycles. Therefore, higher overvoltages have to be applied beyond the stability window of carbonate-based electrolytes to achieve the full charge and discharge states in such batteries. There is also an opinion that solid electrolyte interfaces (SEIs), in particular, formed at the anode, are not stable in the case of using carbonate-type electrolytes. ${ }^{32}$ However, the impacts of solvent and electrolyte salts on the properties of SEIs formed in K-ion batteries during their operation remain poorly understood. Yet, from previous work in our group and others on K-ion batteries, we have found that diglyme (DG), 1,3-dioxolane (DOL), 1,2dimethoxyethane (DME), and fluorinated carbonates (e.g., fluoroethylene carbonate (FEC)) are generally suitable as the most preferred electrolyte solvents. ${ }^{32-36}$

In this work, we show that the choice of an appropriate electrolyte represents a crucial issue for achieving a superior performance of K-ion batteries with p-DPPZ cathodes. To find an optimal solution, a broad range of the electrolyte formulations were screened, as shown in Figure 1. In short, $\mathrm{KPF}_{6}$ solutions in a $1: 1 \mathrm{v} / \mathrm{v}$ mixture of $\mathrm{EC}$ with diethylcarbonate (EC/DEC), 1:1 v/v mixture of FEC/DMC, as well as in pure DG and DME were chosen as basic electrolyte formulations for K-ion batteries with p-DPPZ cathodes. We note that low cycling stability and poor rate capabilities were observed for the cells assembled with $0.5 \mathrm{M}$ $\mathrm{KPF}_{6}$ in EC/DEC, which is in line with the previously reported results for this electrolyte composition. ${ }^{31}$ On the contrary, $1 \mathrm{M}$ $\mathrm{KPF}_{6}$ solution in $\mathrm{FEC} / \mathrm{DMC}$ afforded the highest specific capacity at the lowest current density of $40 \mathrm{~mA} \mathrm{~g}^{-1}$, but it strongly decayed at higher current densities. The $1 \mathrm{M}$ solution of $\mathrm{KPF}_{6}$ in DG showed a superior performance compared with $1 \mathrm{M} \mathrm{KPF}_{6}$ in DME. It is known that using highly concentrated electrolyte solutions usually improves the overall performance of potassium batteries. ${ }^{37-39} \mathrm{DG}$ was chosen as the solvent for $\mathrm{KPF}_{6}$ salt, which allowed for the preparation of a $2.2 \mathrm{M}$ concentration of the electrolyte. 


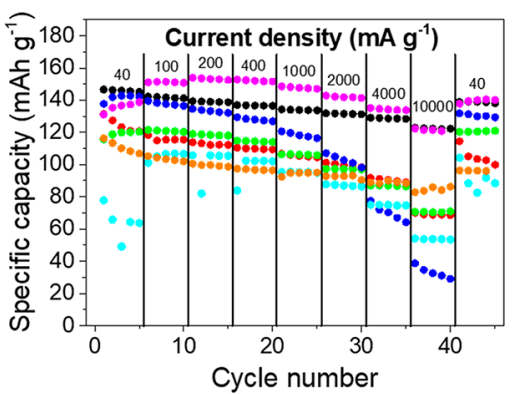

Figure 1. Capacity versus current density behavior of $\mathrm{p}-\mathrm{DPPZ} / / \mathrm{K}$ half-cells with different electrolyte formulations: $0.5 \mathrm{M} \mathrm{KPF}_{6}$ in EC/ DEC (red), $1 \mathrm{M} \mathrm{KPF}_{6}$ in diglyme (green), $1 \mathrm{M} \mathrm{KPF}_{6}$ in FEC/DMC (blue), $1 \mathrm{M} \mathrm{KPF}_{6}$ in DME (cyan), $2.2 \mathrm{M} \mathrm{KPF}_{6}$ in diglyme (magenta), and $2 \mathrm{M}$ KTFSI in diglyme (orange). Characteristics of the p$\mathrm{DPPZ} / / \mathrm{Li}$ half cells with $1 \mathrm{M} \mathrm{LiPF}_{6}$ in $\mathrm{EC} / \mathrm{DMC}$ electrolyte are shown for comparison (black).

The cells assembled with a $2.2 \mathrm{M}$ solution of $\mathrm{KPF}_{6}$ in DG demonstrated strongly improved performance. The specific capacity of the cells was rapidly growing during the initial few cycles, suggesting the reorganization of the system, which is tentatively associated with a high viscosity of the electrolyte, limiting the rate of its penetration into the cathode composite. The capacity increased at higher current densities, reaching the maximal value of $154 \mathrm{mAh} \mathrm{g}^{-1}$ at $200 \mathrm{~mA} \mathrm{~g}^{-1}$. Replacing the $\mathrm{KPF}_{6}$ with potassium bis(trifluoromethylsulfonyl)imide (KTFSI) while preserving the $\sim 2 \mathrm{M}$ salt concentration did not improve the results, suggesting that the smaller hexafluorophosphate anion probably has better compatibility with the p-DPPZ cathode framework because anions are penetrating into the polymer cathode while charging.

Particular attention should be paid to the high rate capability revealed by the cells with the $2.2 \mathrm{M} \mathrm{KPF}_{6}$ in DG electrolyte, demonstrating exceptional specific capacities of 122-135 mAh $\mathrm{g}^{-1}$ at current densities as high as $4-10 \mathrm{~A} \mathrm{~g}^{-1}$. Interestingly, the K-ion cells in terms of specific capacity and energy density even surpassed the reference $\mathrm{Li}$-ion cells assembled using $1 \mathrm{M}$ $\mathrm{LiPF}_{6}$ in EC/DMC $(1: 1 \mathrm{v} / \mathrm{v})$. The obtained results clearly indicate that $2.2 \mathrm{M} \mathrm{KPF}_{6}$ in $\mathrm{DG}$ represents the optimal electrolyte composition for K-ion batteries comprising $\mathrm{p}-\mathrm{DPPZ}$ cathodes.

Cyclic voltammetry (CV) measurements (Figure 2) demonstrate that the potential range of $2.5-4.5 \mathrm{~V}$ should be considered as optimal for charge-discharge cycling of batteries with p-DPPZ cathodes. The first cycle revealed the group of irreversible oxidation peaks in the range of 3.8 to $4.5 \mathrm{~V}$, which can be attributed to SEI formation processes. X-ray photo-

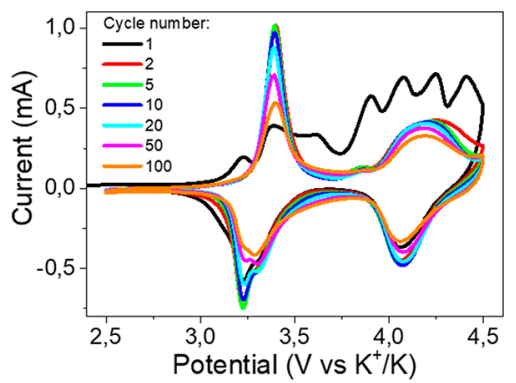

Figure 2. Cyclic voltammograms of p-DPPZ//K half-cell with $2.2 \mathrm{M}$ $\mathrm{KPF}_{6}$ in diglyme electrolyte. electron spectroscopy (XPS) confirmed that SEI was indeed formed atop the p-DPPZ cathode after the first charge/ discharge cycle. This SEI incorporated multiple $\mathrm{C}-\mathrm{O}$ bonds from the electrolyte solvent in combination with $\mathrm{KF}$, most probably released from $\mathrm{KPF}_{6}$ (Figure S2).

Starting from the second cycle, the CV profile exhibits a pair of well-defined narrow redox peaks with a half-wave potential $E_{1 / 2}$ of $3.31 \mathrm{~V}$ due to a single electron oxidation of each of the dihydrophenazine units. This process can also be interpreted as the conversion of every second 1,4-phenylenediamine moiety in the main polymer chain to the corresponding quinoneimine (Scheme 2). Another set of broad peaks with $E_{1 / 2}=4.16 \mathrm{~V}$ is rather typical for (quasi)conjugated polymers ${ }^{28}$ and corresponds to the further oxidation of each of the monomer units in p-DPPZ, thus converting all 1,4-phenylenediamine fragments to quinoneimines (Scheme 2). The presence of some additional minor redox peaks with an evident splitting of the main reduction peak at $3.23 \mathrm{~V}$ is apparently related to the unavoidable polydispersity and the presence of defect sites or end-capping groups in the polymer chains, which show a somewhat different electrochemical behavior due to the different chemical "surroundings".

The electrochemical behavior of $\mathrm{p}-\mathrm{DPPZ}$ cathode was further investigated by the galvanostatic charge-discharge cycling of $\mathrm{K} / / \mathrm{p}$-DPPZ half-cells assembled using the optimized electrolyte $\left(2.2 \mathrm{M} \mathrm{KPF}_{6}\right.$ in $\left.\mathrm{DG}\right)$ in the voltage range of $2.5-4.5 \mathrm{~V}$ (Figure 3). Two discharge plateaus at 4.1 and $3.3 \mathrm{~V}$ can be distinguished on the charge-discharge curves (Figure 3a), which is in a good agreement with the CV data. The average cell discharge potential of $\sim 3.6 \mathrm{~V}$ was considerably higher than that of all previously reported K-ion batteries with organic cathodes. Moreover, this value is comparable to the discharge potentials of the most promising inorganic cathodes based on PB analogs.

The p-DPPZ cathodes also demonstrated high gravimetric capacities of 155,142 , and $127 \mathrm{mAh} \mathrm{g}^{-1}$ in the first cycle while charged and discharged at current densities of 200, 400, and $1000 \mathrm{~mA} \mathrm{~g}^{-1}$, respectively (Figure $3 \mathrm{~b}$ ). The highest capacity of $162 \mathrm{mAh} \mathrm{g}^{-1}$ was achieved at the current density of $200 \mathrm{~mA}$ $\mathrm{g}^{-1}(\sim 1 \mathrm{C}$ rate) , which exceeds the best values delivered by the commonly used lithium-ion batteries with $\mathrm{LiFePO}_{4}$ cathodes operating even at lower discharge rates. ${ }^{40}$ This example illustrates that cheaper potassium-ion batteries with organic cathodes are now demonstrating a comparable performance to the industrial Li-ion benchmarks.

Notably, p-DPPZ cathodes show some initial activation reflected in a gradual improvement of the specific capacity and Coulombic efficiency within the first 10-20 cycles. We believe that such behavior is associated with the use of a concentrated and viscous electrolyte, which likely slowly penetrates into the cathode framework upon cycling. Indeed, using less concentrated $1 \mathrm{M} \mathrm{KPF}_{6}$ in $\mathrm{DG}$ as the electrolyte significantly suppressed this activation behavior (Figure 1). Alternatively, reduced specific capacity and Coulombic efficiency can be associated with the formation of SEI atop p-DPPZ cathodes, as revealed by XPS (Figure S2). Moreover, the behavior of the Coulombic efficiency in the initial cycles is strongly electrolytedependent, which also points to the irreversible processes leading to the SEI formation (Figure S3).

In terms of cyclability, the $\mathrm{p}-\mathrm{DPPZ} / / \mathrm{K}$ cells showed a decent capacity retention of $92\left(200 \mathrm{~mA} \mathrm{~g}^{-1}\right), 93(400 \mathrm{~mA}$ $\left.\mathrm{g}^{-1}\right), 95\left(1000 \mathrm{~mA} \mathrm{~g}^{-1}\right)$, and $96 \%\left(2000 \mathrm{~mA} \mathrm{~g}^{-1}\right)$ after 100 charge/discharge cycles (Figure 3c). While cycling the 
Scheme 2. Redox Transformations of p-DPPZ
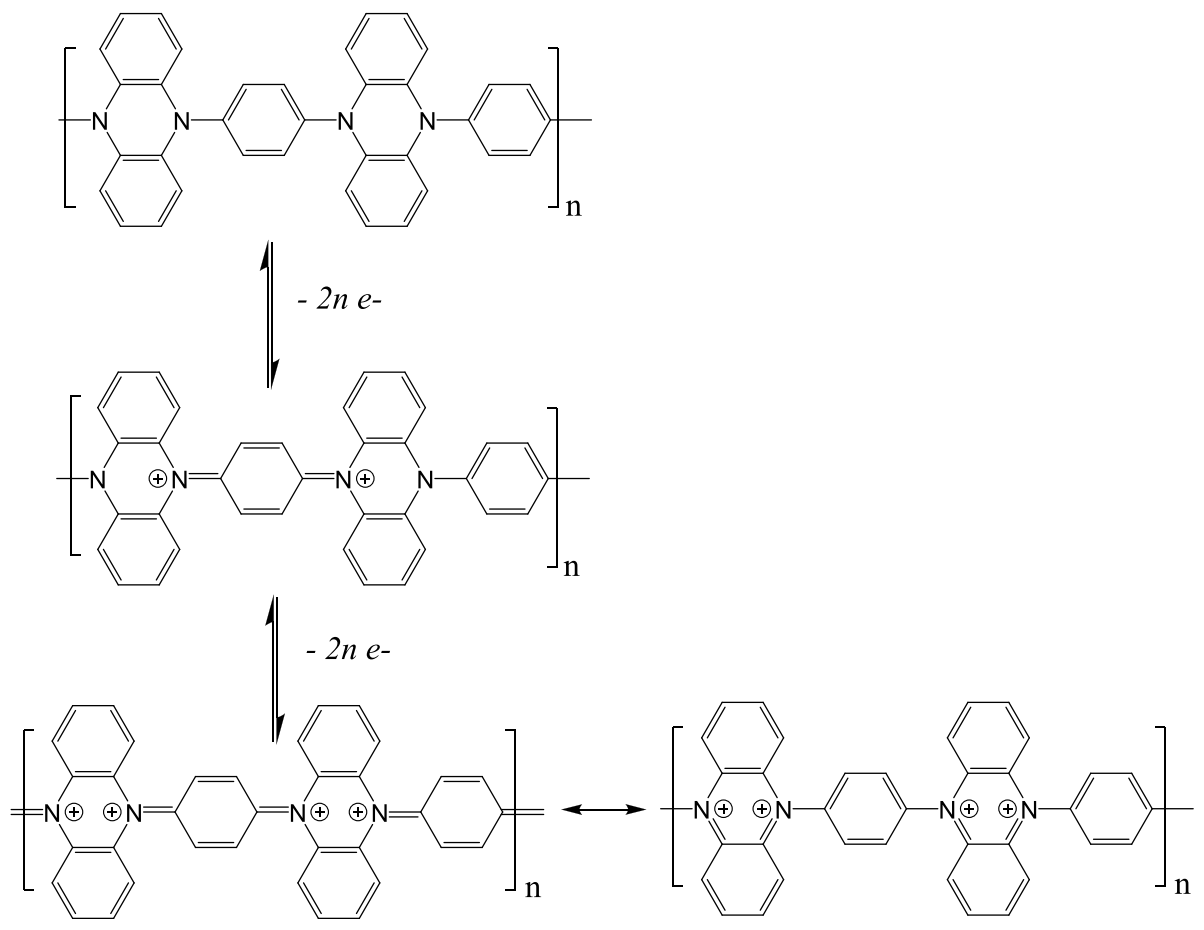

a

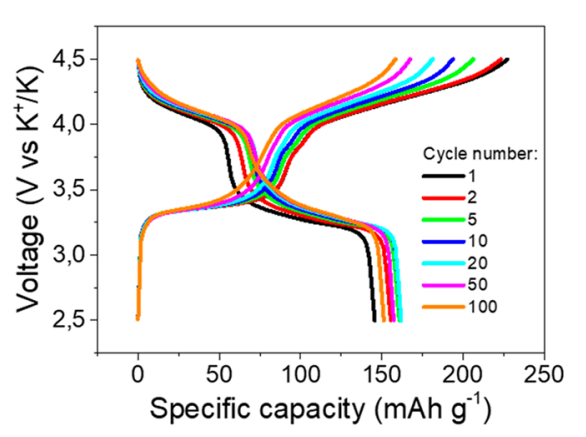

$b$

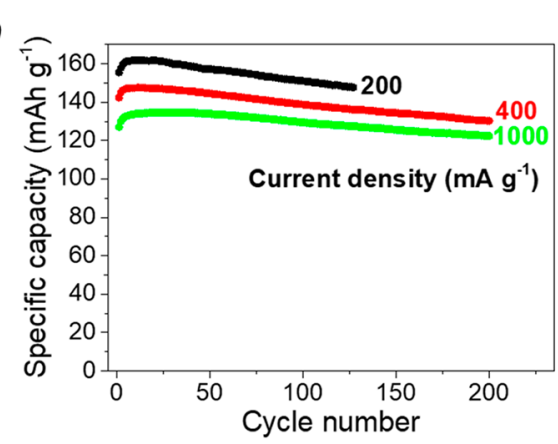

$c$

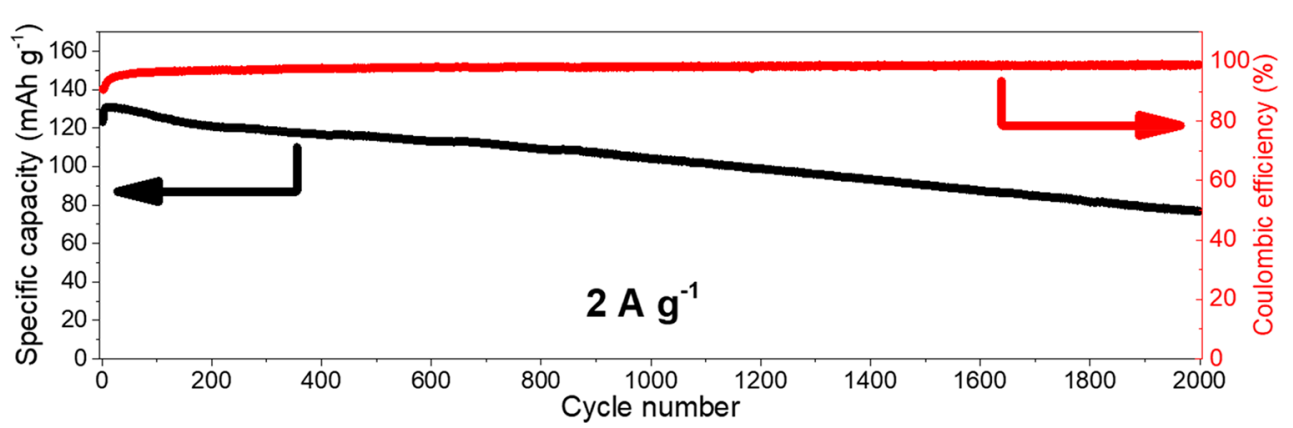

Figure 3. Electrochemical characteristics of K-ion batteries with p-DPPZ cathode and $2.2 \mathrm{M} \mathrm{KPF}_{6}$ in diglyme electrolyte cycled in the voltage range of 2.5-4.5 V: (a) charge-discharge characteristics at $200 \mathrm{~mA} \mathrm{~g}^{-1}$ current density, (b) evolution of specific capacity under cycling at different current densities, and (c) long-term cycling stability of cell at current density of $2 \mathrm{~A} \mathrm{~g}^{-1}$.

batteries at high current density of $2 \mathrm{~A} \mathrm{~g}^{-1}$, the maximum specific capacity was $131 \mathrm{mAh} \mathrm{g}^{-1}$ with a retention of 79 and $59 \%$ of this value after 1000 and 2000 cycles, respectively. The Coulombic efficiency was maintained at 99 to $100 \%$ for at least 2000 cycles at $2 \mathrm{~A} \mathrm{~g}^{-1}$. The observed gradual capacity decay is most likely related to the partial dissolution of the cathode material in the electrolyte, as was concluded from the appearance of a colored substance on the separator of the battery disassembled after $\sim 1000$ cycles (Figure S1). We strongly believe that the operational stability of these batteries can be substantially improved upon further optimization of the synthesis of the material and battery manufacturing technology.

$\mathrm{p}$-DPPZ//K cells with the optimized electrolyte demonstrated a rather remarkable rate capability. Figure $4 \mathrm{a}$ shows charge-discharge curves recorded at different current densities. The specific capacity decreases from $\sim 153$ to 123 $\mathrm{mAh} \mathrm{g}^{-1}$ while the current density is increased 50 -fold from 
a
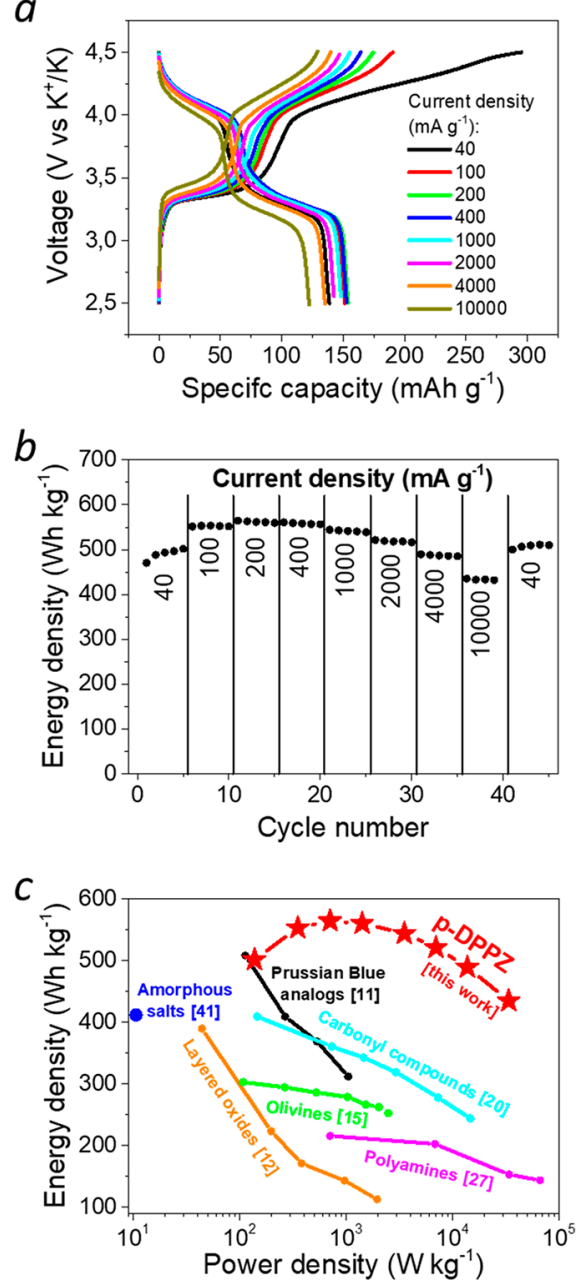

Figure 4. (a) Charge-discharge characteristics and (b) energy density of K-ion batteries with p-DPPZ cathode at different current densities. (c) Chart showing the energy density versus power density performance of $\mathrm{p}$-DPPZ polymeric cathode reported here compared with the best literature benchmarks of organic and inorganic cathodes reported so far for K-ion batteries.

$200 \mathrm{~mA} \mathrm{~g}^{-1}$ to $10 \mathrm{~A} \mathrm{~g}^{-1}$. Because the current density of $10 \mathrm{~A}$ $\mathrm{g}^{-1}$ corresponds to $\sim 80 \mathrm{C}$ rate (considering the practical specific capacity), the full charge or discharge of the battery can be performed in $<1 \mathrm{~min}$. There is a strong demand for such ultrafast batteries to match the current level of the development of various portable electronics and electric vehicles, which need the batteries to be charged in minutes rather than hours.

Figure $4 \mathrm{~b}$ shows that $\mathrm{p}-\mathrm{DPPZ} / / \mathrm{K}$ batteries deliver the highest energy density of $564 \mathrm{Wh} \mathrm{kg}^{-1}$ at the current density of $200 \mathrm{~mA} \mathrm{~g}^{-1}(\sim 1 \mathrm{C}$ current rate). Champion cells showing the specific capacity of $162 \mathrm{mAh} \mathrm{g}^{-1}$ (Figure $3 \mathrm{~b}$ ) provide an even higher energy density of $593 \mathrm{Wh} \mathrm{kg}^{-1}$. To the best of our knowledge, these are record values among all reported inorganic and organic cathodes evaluated so far in K-ion batteries. Furthermore, the revealed performance of p-DPPZ// $\mathrm{K}$ cells in the context of both energy and power density is particularly exciting, as one can conclude from the comparison chart shown in Figure 4c. The demonstrated power density of $>10^{4} \mathrm{~W} \mathrm{~kg} \mathrm{~kg}^{-1}$ makes the $\mathrm{p}-\mathrm{DPPZ} / / \mathrm{K}$ batteries behaving similarly to supercapacitors while still maintaining the highenergy density of metal-ion batteries.
In summary, we have demonstrated for the first time that polyarylamine $\mathrm{p}-\mathrm{DPPZ}$ as a cathode for K-ion batteries with an optimized electrolyte composition can achieve record-high performance characteristics for this new type of energy storage devices. Indeed, p-DPPZ delivered superior energy and power density in combination with a good operation stability during charge/discharge cycling, which are the most important prerequisites for considering further practical applications. Importantly, $\mathrm{p}-\mathrm{DPPZ}$ in potassium-ion cells showed a comparable energy density to that of conventional $\mathrm{LiFePO}_{4}$ cathodes, which are massively used in the lithium battery industry. This clearly illustrates that the rapid development of $\mathrm{K}$-ion batteries has now brought them very close to the Li-ion industrial benchmarks. In that context, the design of advanced organic cathodes such as $\mathrm{p}-\mathrm{DPPZ}$ reported here might play an important role in the commercialization of the emerging K-ion battery technology.

\section{ASSOCIATED CONTENT}

Supporting Information

The Supporting Information is available free of charge on the ACS Publications website at DOI: 10.1021/acs.jpclett.9b02039.

Experimental procedures and methods for material synthesis, cathode fabrication, cell assembling, and electrochemical testing (PDF)

\section{AUTHOR INFORMATION}

\section{Corresponding Author}

*E-mail: troshin2003@inbox.ru.

ORCID ${ }^{\circ}$

Ivan Zhidkov: 0000-0001-8727-4730

Keith J. Stevenson: 0000-0002-1082-2871

Pavel A. Troshin: 0000-0001-9957-4140

Notes

The authors declare no competing financial interest.

\section{ACKNOWLEDGMENTS}

This work was supported by Russian Science Foundation, project 16-13-00111. We acknowledge the support of Dr. A. Mumyatov with FTIR spectroscopy measurements. The XPS measurements were supported by the Government of Russian Federation (Act 211, Agreement No. 02.A03.21.0006) and Theme "Electron" (no. AAAA-A18-118020190098-5).

\section{REFERENCES}

(1) Tarascon, J.-M.; Armand, M. Issues and Challenges Facing Rechargeable Lithium Batteries. Nature 2001, 414 (6861), 359-367.

(2) Taylor, S. R.; McLennan, S. M. The Continental Crust: Its Composition and Evolution: An Examination of the Geochemical Record Preserved in Sedimentary Rocks; Blackwell Science: Oxford, U.K., 1985.

(3) Song, Z.; Zhou, H. Towards Sustainable and Versatile Energy Storage Devices: An Overview of Organic Electrode Materials. Energy Environ. Sci. 2013, 6 (8), 2280.

(4) Azevedo, M.; Campagnol, N.; Hagenbruch, T.; Hoffman, K.; Lala, A.; Ramsbottom, O. Lithium and Cobalt: A Tale of Two Commodities. https://www.mckinsey.com/industries/metals-andmining/our-insights/lithium-and-cobalt-a-tale-of-two-commodities (accessed June 28, 2019).

(5) Zhang, J.; Liu, T.; Cheng, X.; Xia, M.; Zheng, R.; Peng, N.; Yu, H.; Shui, M.; Shu, J. Development Status and Future Prospect of Non-Aqueous Potassium Ion Batteries for Large Scale Energy Storage. Nano Energy 2019, 60, 340-361. 
(6) Hwang, J.-Y.; Myung, S.-T.; Sun, Y.-K. Recent Progress in Rechargeable Potassium Batteries. Adv. Funct. Mater. 2018, 28 (43), 1802938.

(7) Xu, Y.-S.; Duan, S.-Y.; Sun, Y.-G.; Bin, D.-S.; Tao, X.-S.; Zhang, D.; Liu, Y.; Cao, A.-M.; Wan, L.-J. Recent Developments in Electrode Materials for Potassium-Ion Batteries. J. Mater. Chem. A 2019, 7 (9), 4334-4352.

(8) Eftekhari, A. Potassium Secondary Cell Based on Prussian Blue Cathode. J. Power Sources 2004, 126 (1-2), 221-228.

(9) Piernas-Muñoz, M. J.; Castillo-Martínez, E.; Bondarchuk, O.; Armand, M.; Rojo, T. Higher Voltage Plateau Cubic Prussian White for Na-Ion Batteries. J. Power Sources 2016, 324, 766-773.

(10) He, G.; Nazar, L. F. Crystallite Size Control of Prussian White Analogues for Nonaqueous Potassium-Ion Batteries. ACS Energy Lett. 2017, 2 (5), 1122-1127.

(11) Xue, L.; Li, Y.; Gao, H.; Zhou, W.; Lü, X.; Kaveevivitchai, W.; Manthiram, A.; Goodenough, J. B. Low-Cost High-Energy Potassium Cathode. J. Am. Chem. Soc. 2017, 139 (6), 2164-2167.

(12) Wang, X.; Xu, X.; Niu, C.; Meng, J.; Huang, M.; Liu, X.; Liu, Z.; Mai, L. Earth Abundant Fe/Mn-Based Layered Oxide Interconnected Nanowires for Advanced K-Ion Full Batteries. Nano Lett. 2017, 17 (1), 544-550.

(13) Kim, H.; Seo, D.-H.; Kim, J. C.; Bo, S.-H.; Liu, L.; Shi, T.; Ceder, G. Investigation of Potassium Storage in Layered P3-Type $\mathrm{K}_{0.5} \mathrm{MnO}_{2}$ Cathode. Adv. Mater. 2017, 29 (37), 1702480.

(14) Vaalma, C.; Giffin, G. A.; Buchholz, D.; Passerini, S. NonAqueous K-Ion Battery Based on Layered $\mathrm{K}_{0.3} \mathrm{MnO}_{2}$ and Hard Carbon/Carbon Black. J. Electrochem. Soc. 2016, 163 (7), A1295A1299.

(15) Chihara, K.; Katogi, A.; Kubota, K.; Komaba, S. $\mathrm{KVPO}_{4} \mathrm{~F}$ and $\mathrm{KVOPO}_{4}$ toward $4 \mathrm{~V}$-Class Potassium-Ion Batteries. Chem. Commun. 2017, 53 (37), 5208-5211.

(16) Park, W. B.; Han, S. C.; Park, C.; Hong, S. U.; Han, U.; Singh, S. P.; Jung, Y. H.; Ahn, D.; Sohn, K.-S.; Pyo, M. $\mathrm{KVP}_{2} \mathrm{O}_{7}$ as a Robust High-Energy Cathode for Potassium-Ion Batteries: Pinpointed by a Full Screening of the Inorganic Registry under Specific Search Conditions. Adv. Energy Mater. 2018, 8 (13), 1703099.

(17) Liang, Y.; Tao, Z.; Chen, J. Organic Electrode Materials for Rechargeable Lithium Batteries. Adv. Energy Mater. 2012, 2 (7), 742769.

(18) Deng, W.; Liang, X.; Wu, X.; Qian, J.; Cao, Y.; Ai, X.; Feng, J.; Yang, H. A Low Cost, All-Organic Na-Ion Battery Based on Polymeric Cathode and Anode. Sci. Rep. 2013, 3, 2671.

(19) Xu, Y.; Zhou, M.; Lei, Y. Organic Materials for Rechargeable Sodium-Ion Batteries. Mater. Today 2018, 21 (1), 60-78.

(20) Tang, M.; Wu, Y.; Chen, Y.; Jiang, C.; Zhu, S.; Zhuo, S.; Wang, C. An Organic Cathode with High Capacities for Fast-Charge Potassium-Ion Batteries. J. Mater. Chem. A 2019, 7 (2), 486-492.

(21) Tian, B.; Zheng, J.; Zhao, C.; Liu, C.; Su, C.; Tang, W.; Li, X.; Ning, G.-H. Carbonyl-Based Polyimide and Polyquinoneimide for Potassium-Ion Batteries. J. Mater. Chem. A 2019, 7 (16), 999710003.

(22) Jian, Z.; Liang, Y.; Rodríguez-Pérez, I. A.; Yao, Y.; Ji, X. Poly(Anthraquinonyl Sulfide) Cathode for Potassium-Ion Batteries. Electrochem. Commun. 2016, 71, 5-8.

(23) Chen, Y.; Luo, W.; Carter, M.; Zhou, L.; Dai, J.; Fu, K.; Lacey, S.; Li, T.; Wan, J.; Han, X.; et al. Organic Electrode for Non-Aqueous Potassium-Ion Batteries. Nano Energy 2015, 18, 205-211.

(24) Zhou, M.; Liu, M.; Wang, J.; Gu, T.; Huang, B.; Wang, W.; Wang, K.; Cheng, S.; Jiang, K. Polydiaminoanthraquinones with Tunable Redox Properties as High Performance Organic Cathodes for K-Ion Batteries. Chem. Commun. 2019, 55, 6054-6057.

(25) Cao, R.; Qian, J.; Zhang, J.-G.; Xu, W. Organic Cathode Materials for Rechargeable Batteries. In Rechargeable Batteries. Materials, Technologies and New Trends; Zhang, Z., Zhang, S. S., Eds.; Springer International Publishing, 2015; p 637.

(26) Feng, J. K.; Cao, Y. L.; Ai, X. P.; Yang, H. X. Polytriphenylamine: A High Power and High Capacity Cathode Material for
Rechargeable Lithium Batteries. J. Power Sources 2008, 177 (1), 199204.

(27) Yamamoto, K.; Suemasa, D.; Masuda, K.; Aita, K.; Endo, T. Hyperbranched Triphenylamine Polymer for UltraFast Battery Cathode. ACS Appl. Mater. Interfaces 2018, 10 (7), 6346-6353.

(28) Obrezkov, F. A.; Shestakov, A. F.; Traven, V. F.; Stevenson, K. J.; Troshin, P. A. An Ultrafast Charging Polyphenylamine-Based Cathode Material for High Rate Lithium, Sodium and Potassium Batteries. J. Mater. Chem. A 2019, 7 (18), 11430-11437.

(29) Fan, L.; Liu, Q.; Xu, Z.; Lu, B. An Organic Cathode for Potassium Dual-Ion Full Battery. ACS Energy Lett. 2017, 2 (7), 16141620.

(30) Dai, G.; Wang, X.; Qian, Y.; Niu, Z.; Zhu, X.; Ye, J.; Zhao, Y.; Zhang, X. Manipulation of Conjugation to Stabilize N Redox-Active Centers for the Design of High-Voltage Organic Battery Cathode. Energy Storage Mater. 2019, 16, 236-242.

(31) Choi, N. S.; Han, J. G.; Ha, S. Y.; Park, I.; Back, C. K. Recent Advances in the Electrolytes for Interfacial Stability of High-Voltage Cathodes in Lithium-Ion Batteries. RSC Adv. 2015, 5 (4), 27322748.

(32) Zhao, H.; Xu, J.; Yin, D.; Du, Y. Electrolytes for Batteries with Earth-Abundant Metal Anodes. Chem. - Eur. J. 2018, 24 (69), 1822018234.

(33) Schroder, K.; Alvarado, J.; Yersak, T. A.; Li, J.; Dudney, N.; Webb, L. J.; Meng, Y. S.; Stevenson, K. J. The Effect of Fluoroethylene Carbonate as an Additive on the Solid Electrolyte Interphase on Silicon Lithium-Ion Electrodes. Chem. Mater. 2015, 27 (16), 5531-5542.

(34) Xiao, N.; Mcculloch, W. D.; Wu, Y. Reversible Dendrite-Free Potassium Plating and Stripping Electrochemistry for Potassium Secondary Batteries. J. Am. Chem. Soc. 2017, 139, 9475-9478.

(35) Lei, K.; Li, F.; Mu, C.; Wang, J.; Zhao, Q.; Chen, C.; Chen, J. High K-Storage Performance Based on the Synergy of Dipotassium Terephthalate and Ether-Based Electrolyte. Energy Environ. Sci. 2017, $10,552-557$.

(36) Katorova, N. S.; Fedotov, S. S.; Rupasov, D. P.; Luchinin, N. D.; Delattre, B.; Chiang, Y.; Abakumov, A. M.; Stevenson, K. J. Effect of Concentrated Diglyme-Based Electrolytes on the Electrochemical Performance of Potassium-Ion Batteries. ACS Appl. Energy Mater. 2019, 2, 6051-6059, DOI: 10.1021/acsaem.9b01173.

(37) Leonard, D. P.; Wei, Z.; Chen, G.; Du, F.; Ji, X. Water-in-Salt Electrolyte for Potassium-Ion Batteries. ACS Energy Lett. 2018, 3 (2), 373-374.

(38) Zeng, G.; Xiong, S.; Qian, Y.; Ci, L.; Feng, J. Non-Flammable Phosphate Electrolyte with High Salt-to-Solvent Ratios for Safe Potassium-Ion Battery. J. Electrochem. Soc. 2019, 166 (6), A1217A1222.

(39) Zhang, R.; Bao, J.; Wang, Y.; Sun, C.-F. Concentrated Electrolytes Stabilize Bismuth-Potassium Batteries. Chem. Sci. 2018, 9 (29), 6193-6198.

(40) Cabán-Huertas, Z.; Ayyad, O.; Dubal, D. P.; Gómez-Romero, P. Aqueous Synthesis of $\mathrm{LiFePO}_{4}$ with Fractal Granularity. Sci. Rep. 2016, 6, 27024.

(41) Mathew, V.; Kim, S.; Kang, J.; Gim, J.; Song, J.; Baboo, J. P.; Park, W.; Ahn, D.; Han, J.; Gu, L.; et al. Amorphous Iron Phosphate: Potential Host for Various Charge Carrier Ions. NPG Asia Mater. 2014, 6 (10), e138-e138. 